Original Research Article

\title{
Drug utilization study of antihypertensive drugs used in the treatment of second and third trimester of pregnancy in tertiary care hospital
}

\author{
Shrikant B. Lahamate*, Syed U. Razvi, Mirza S. Baig, Sudhakar M. Doifode
}

Department of Pharmacology, Govt. Medical College, Aurangabad, Maharashtra, India

Received: 21 June 2018

Accepted: 26 July 2018

*Correspondence to:

Dr. Shrikant B. Lahamate, Email: shri.lahamate73@ gmail.com

Copyright: (C) the author(s), publisher and licensee Medip Academy. This is an openaccess article distributed under the terms of the Creative Commons Attribution NonCommercial License, which permits unrestricted noncommercial use, distribution, and reproduction in any medium, provided the original work is properly cited.

\begin{abstract}
Background: Hypertensive disorders are major cause of the perinatal and maternal mortality and morbidity worldwide. Aim of study was to evaluate current trend of antihypertensive drugs and to assess frequency and distribution of antihypertensive drugs in pregnancy.

Methods: A retrospective observational study was conducted in a tertiary care hospital for period of six months in collaboration with department of obstetrics and gynaecology. Patients data recorded in case report form and analysed to study prescription pattern and related information.

Results: Total of 104 cases were enrolled in this study. Prescribed antihypertensive drugs in pregnancy were Labetalol, Nifedipine, $\mathrm{MgSO}_{4}$ and furosemide. Most commonly prescribed drug was labetalol. In this study, Gestational hypertension was most common diagnosis in hypertensive disorder. Majority of drug prescribed from category $\mathrm{C}$ and A. In present study, Single drug therapy was most commonly prescribed for hypertension in pregnancy was $64.42 \%$ whereas multiple drug therapy was $35.57 \%$. Most common maternal complication was anaemia i.e. $54.05 \%$ followed by placental abruption in $24.3 \%$. Neonatal outcome was low birth weight i.e.36\% followed by preterm birth i.e. $24 \%$.

Conclusions: Labetalol found to be most common prescribed drug. Single drug therapy prescription was high as compared to multiple drug therapy prescription in hypertensive disorders in pregnancy. Gestational hypertension was most common cause of hypertensive disorder. Anaemia was found to be most common maternal complication encountered in hypertensive disorders in pregnancy. Most common adverse neonatal outcome was low birth weight.
\end{abstract}

Keywords: Antihypertensive drugs, Drug utilization study, Gestational hypertension, Labetalol, Pregnancy

\section{INTRODUCTION}

Drug utilization studies has purpose to study drug utilization and side effects of drugs in large numbers of people with the purpose of supporting rational and costeffective use of drugs. ${ }^{1}$ Drug utilization study is conducted by health professional due to upcoming of more and more new drugs in the market. There is wide variation in drug prescribing pattern, ADR of drugs and cost-effectiveness of these drugs. ${ }^{2}$
The most common complication worldwide is hypertension in pregnancy which contributes to 5-20\%, of which $2-8 \%$ is in developed country and $10 \%$ or more in developing countries. This complication leads to more perinatal morbidity and mortality and has third most common cause of maternal death worldwide. ${ }^{3}$

Hypertension in pregnancy which is defined as SBP (systolic blood pressure) $\geq 140 \mathrm{mmhg}$ or DBP (diastolic blood pressure) $\geq 90 \mathrm{mmhg}$ or by increase in SBP $\geq 30 \mathrm{mmhg}$ or DBP $\geq 15 \mathrm{mmh}$ from preconception or first 
trimester of pregnancy, which is confirmed by measuring blood pressure six hours apart. ${ }^{4}$

Hypertension disorders in pregnancy are classified as chronic hypertension, gestational hypertension, preeclampsia, eclampsia and superimposition of preeclampsia on chronic hypertension. ${ }^{5}$ In chronic hypertension, blood pressure greater than 140/90mm Hg before pregnancy or before $20^{\text {th }}$ weeks of pregnancy. Gestational hypertension has blood pressure range more than $140 / 90 \mathrm{mmhg}$ after $20^{\text {th }}$ weeks of pregnancy which resolves within 42 days after delivery. ${ }^{6}$ Complication associated with hypertension in pregnancy for foetal, neonatal and maternal outcomes includes preterm birth, intra-uterine growth restriction, perinatal death, acute renal or hepatic failure, ante-partum or post-partum haemorrhages and maternal death. ${ }^{7}$

Selection of antihypertensive drug therapy should depend upon the relative risk and benefits to the pregnant women. In pregnancy with blood pressure greater than 170/90mmhg has a greater risk of cerebrovascular accidents. $^{8}$ Antihypertensive drugs in various combinations are used for management of hypertensive disorders in pregnancy. There is need to observe pattern of antihypertensive drug used and to see if current usage is rational, effective and well tolerated in accordance with current guidelines. ${ }^{9}$

Authors study to evaluate the prescribing patterns of drugs in pregnant women with hypertension in out-patients and inpatient of obstetrics and gynaecology department, so that the economic burden is reduced, the quality of life can be improved and to minimize the harmful effects of drugs in pregnant women and child. ${ }^{10}$

\section{METHODS}

A retrospective observational study was conducted in a tertiary care hospital for period of six months in collaboration with department of obstetrics and gynecology.

Case record sheets of the patients diagnosed with hypertensive disorders in pregnancy in Obstetric OPD or ward during the period July - December 2017 were reviewed. Patients data recorded in case report form and analyzed to study prescription pattern of drug, drug dosage form, number of drugs, dosage of drug, frequency of administration, duration of treatment and complementary indicators were evaluated.

\section{Study objective}

\section{Primary objective}

- To study frequency and different types of antihypertensive drug use in pregnancy with hypertension.

\section{Secondary objective}

- To study and evaluate the prescribing patterns of the antihypertensive drug use in pregnancy with hypertension.

- To study maternal and neonatal complications of antihypertensive drug use in pregnancy with hypertension.

\section{Inclusion criteria}

- Pregnant women with hypertension of age between 18 years to 40 years with or without severe comorbidities.

- $\quad$ Pregnant women with hypertension who are willing to participate in the study.

\section{Exclusion criteria}

- $\quad$ Pregnant women with hypertension with acute and chronic medical condition not secondary to pregnancy.

- Pregnant women with hypertension who are not willing to participate in the study.

\section{Complementary indicators}

- Effect of the drug on the foetus (Low birth Weight, Foetal distress, IUGR, IUD)

- Category and safety of prescribed drugs.

- Definitions used by united states FDA for category of drugs. ${ }^{11}$

\section{Category}

- $\quad$ Category A: Includes drugs that have shown no risk to the foetus after adequate, well controlled studies in pregnant women.

- Category B: Animal studies have revealed no evidence of harm to the foetus or any adverse effect, but adequate and well controlled studies in pregnant women have failed to demonstrate a risk to the foetus.

- Category $C$ : Includes the drugs, which have shown an adverse effect in animal studies or no animal studies have been conducted and there are no adequate and well-controlled studies in pregnant women.

- Category D: There is positive evidence of human foetal risk, but the benefits from use in pregnant women may be acceptable despite the risk (e.g., in a life-threatening situation).

- Category X: Studies in animals or human beings have demonstrated foetal abnormalities or there is evidence of foetal risk based on human experience or both, and the risk of the use drug in pregnant women clearly outweighs any possible benefits. The drug is contraindicated in women who are or may become pregnant. 


\section{RESULTS}

Present study was conducted in OBGY department in which patient from IPD and OPD were studied for a period of six months, in which 104 patients were enrolled and were diagnosed with hypertensive disorder in second and third trimester of pregnancy.

Prescribed antihypertensive drugs in second and third trimester of pregnancy were Labetalol, Nifedipine, MgSO4 and Furosemide. Assessment was done in multiple age group patients of primigravida, second gravida and third gravida having different types of hypertensive disorder in pregnancy. Present study also assesses single drug therapy, multiple drug therapy, types of prescription and frequency of prescription and adverse effect of therapy on maternal and fetal outcomes.

Number of patients in age group 23-26 are more i.e. $36.53 \%$ as comparing to other age group (Table 1).

Table 1: Age wise distribution of patients.

\begin{tabular}{|lll|}
\hline Age groups & No. of patients & Percentage \\
\hline $18-22$ & 34 & $32.69 \%$ \\
\hline $23-26$ & 38 & $36.53 \%$ \\
\hline $27-30$ & 26 & $25 \%$ \\
\hline $31-35$ & 6 & $5.76 \%$ \\
\hline Total & 104 & $100 \%$ \\
\hline
\end{tabular}

Total number of hypertensive disorder highest among second gravida followed by primigravida (Figure 1).

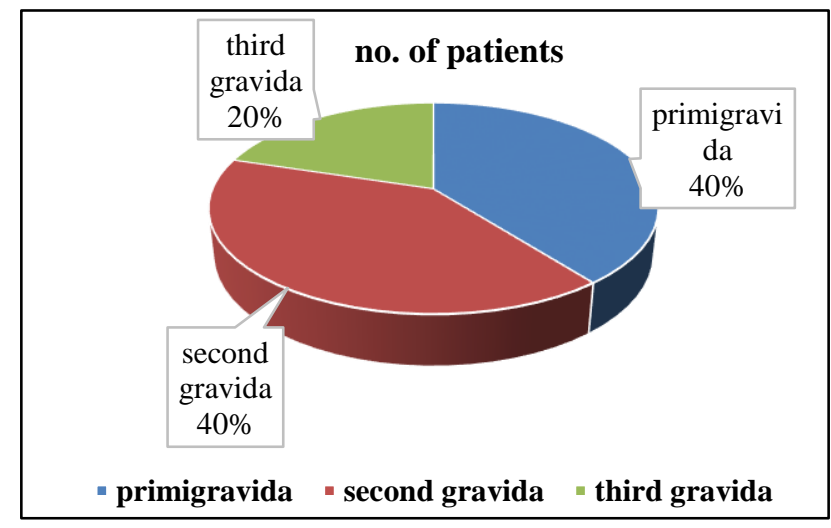

Figure 1: Gravida wise distribution of hypertensive patients.

Mild hypertensive patients are more i.e.63.46\% as compare to moderate and severe hypertension i.e. $29.80 \%$ and $6.7 \%$ respectively (Table 2). Labetalol is the most common drug to be prescribed belongs to FDA category $\mathrm{C}$ in comparison with other drugs like Nifedipine, Furosemide and $\mathrm{MgSO}_{4}$ (Table 3).

Single drug therapy prescription used most commonly i.e. $64.42 \%$ as compared to multiple drug therapy prescription i.e. $35.58 \%$, in hypertensive disorder in pregnancy (Table 4).

Table 2: Classification of patients according to hypertension in pregnancy.

\begin{tabular}{|c|c|c|}
\hline BP (mmHg) & $\begin{array}{l}\text { Number of } \\
\text { patients }\end{array}$ & Percentage \\
\hline 140-159/90-99 (mild) & 66 & $63.46 \%$ \\
\hline $160-179 / 100-109$ (mod) & 31 & $29.80 \%$ \\
\hline$>180 / 110($ severe $)$ & 7 & $6.7 \%$ \\
\hline Total & 104 & $100 \%$ \\
\hline
\end{tabular}

Table 3: No. of antihypertensive drug.

\begin{tabular}{|lll|}
\hline Drug name & No. of drugs & FDA Category \\
\hline Labetalol & 104 & C \\
\hline Nifedipine & 29 & C \\
\hline $\mathrm{MgSO}_{4}$ & 34 & A \\
\hline Furosemide & 15 & C \\
\hline
\end{tabular}

Table 4: Drug therapy in patients of hypertension in pregnancy.

\begin{tabular}{|ll|l|}
\hline Drug therapy & No. of patients & Percentage \\
\hline Single drug & 67 & $64.42 \%$ \\
\hline Double drug & 11 & $10.57 \%$ \\
\hline Triple drug & 11 & $10.57 \%$ \\
\hline More than 3 drug & 15 & $14.42 \%$ \\
\hline Total & 104 & $100 \%$ \\
\hline
\end{tabular}

Most frequently used combination drug therapy is Labetalol + Nifedipine $+\mathrm{MgSO}_{4}+$ Furosemide i.e. $40.54 \%$ as compared to other combination drug therapy in hypertensive disorder in pregnancy (Table 5).

Table 5: Combination therapy of antihypertensive drugs.

\begin{tabular}{|lll|}
\hline Combination therapy & $\begin{array}{l}\text { No. of } \\
\text { participant }\end{array}$ & \begin{tabular}{l} 
Percentage \\
\hline Labetalol + Nifedipine
\end{tabular} \\
\hline Labetalol + $\mathrm{MgSO}_{4}$ & 8 & $8.1 \%$ \\
\hline $\begin{array}{l}\text { Labetalol + Nifedipine + } \\
\mathrm{MgSO}_{4}\end{array}$ & 11 & $21.62 \%$ \\
\hline $\begin{array}{l}\text { Labetalol + Nifedipine + } \\
\mathrm{MgSO}_{4}+\text { Furosemide }\end{array}$ & 15 & $29.72 \%$ \\
\hline Total & 37 & $40.54 \%$ \\
\hline
\end{tabular}

In hypertensive disorders in pregnancy, gestational hypertension found in a greater number of patients followed by non-severe pre-eclampsia. (Figure 2).

Most common maternal complication was anemia i.e. $54.05 \%$ followed by placental abruption i.e.24.3\% (Table 6). Most common neonatal outcome was low birth weight i.e. $36 \%$ followed by preterm birth i.e. $24 \%$ (Table 7). 


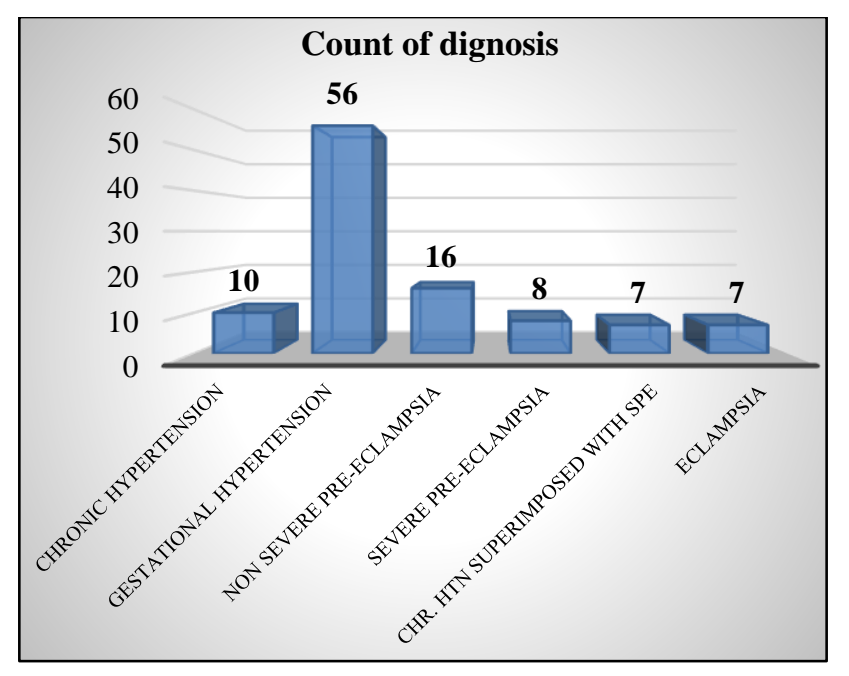

Figure 2: Types of hypertensive disorders in pregnancy.

Table 6: Maternal complications due to hypertension in pregnancy.

\begin{tabular}{|lll|}
\hline $\begin{array}{l}\text { Maternal } \\
\text { complication }\end{array}$ & $\begin{array}{l}\text { Number of } \\
\text { patients }\end{array}$ & Percentage \\
\hline Anaemia & 20 & $54.05 \%$ \\
\hline Placental abruption & 9 & $24.3 \%$ \\
\hline Eclampsia & 4 & $10.81 \%$ \\
\hline Oligohydramnios & 3 & $8.1 \%$ \\
\hline Polyhydramnios & 1 & $2.7 \%$ \\
\hline Total & 37 & $100 \%$ \\
\hline
\end{tabular}

Table 7: Neonatal outcomes.

\begin{tabular}{|ll|l|}
\hline Neonatal outcome & No. of patients & Percentage \\
\hline Foetal distress & 4 & $16 \%$ \\
\hline IUD & 1 & $4 \%$ \\
\hline IUGR & 5 & $20 \%$ \\
\hline Low birth weight & 9 & $36 \%$ \\
\hline Preterm birth & 6 & $24 \%$ \\
\hline Total & 25 & $100 \%$ \\
\hline
\end{tabular}

\section{DISCUSSION}

As hypertensive disorders of pregnancy were major problems worldwide leading to increase in perinatal and maternal morbidity and mortality. ${ }^{12}$ So this study was conducted in patients with hypertension disorders in second and third trimester of pregnancy.

Hypersensitive disorders in pregnancy was highest among second gravida i.e. $40 \%$ followed by primigravida i.e. $40 \%$, correlates with Naveen kumar et al, and Tanuja et al.,13

In present study, hypertensive disorders is seen more commonly in age group 23-26 years (mean age 24.6 \pm ) of patients, which is more similar with study conducted by Sajith $\mathrm{M}$ and Nadkarni $\mathrm{S}$ and also similar with study conducted by Tirthankar and Kumar TN affected most commonly in age group of 21-25 year in patients. ${ }^{13-15}$

In this study, the most commonly prescribed first line antihypertensive drug was labetalol which also correlates with Naveen Kumar et al. Single drug therapy which was most commonly used i.e. $64.42 \%$ followed by multiple drug therapy which also correlates with Naveen Kumar et al. $^{13}$

In present study, the most common maternal complication was anaemia i.e. $54 \%$ followed by placental abruption i.e. $24.3 \%$ as compared with Sajith $M$ which has preeclampsia and compared with Kumar $\mathrm{TN}$ which has eclampsia as a most common complication. ${ }^{13,14}$ Most common neonatal outcome was low birth weight i.e.36\% followed by preterm birth i.e. $24 \%$ which is near about same, when correlates with Naveen Kumar et al, study. ${ }^{13}$

\section{CONCLUSION}

This study give us an idea regarding the prescription pattern and adverse drug events of drugs used in hypertensive disorders of pregnancy. Labetalol found to be most common prescribed drug. Single drug therapy prescription was high as compared to multiple drug therapy prescription in hypertensive disorders in pregnancy. Gestational hypertension was most common cause of hypertensive disorder. Anaemia was found to be most common maternal complication encountered in hypertensive disorders in pregnancy which was due to antihypertensive drugs or maternal hypertension or pregnancy. Most common adverse neonatal outcome was low birth weight.

\section{ACKNOWLEDGEMENTS}

Author and his team would like to thank to HOD and all staff members in department of obstetrics and gynecology, tertiary care hospital, govt. medical college, Aurangabad for their good support and co-operation during the study.

\section{Funding: No funding sources}

Conflict of interest: None declared

Ethical approval: The study was approved by the Institutional Ethics Committee

\section{REFERENCES}

1. Abubakar K, Adbulkadir R, Abubakar SB, Jomih AO, Ugwah-Oguejiofor JC, Danzaki AM. Drug utilization pattern in pregnancy in a tertiary hospital in Sokoto, North West. J Heal Sci [Internet]. 2014;4(4):99-104. Available at: http://article.sapub.org/pdf/10.5923.j.health.2014040 4.04.pdf

2. Hooli TV, Santoshkumar J, Manjunath S, Vinodkumar CS. Drug utilization study of antihypertensives in obstetric practice in a tertiary care hospital Objectives. To evaluate the drug utilization of antihypertensive in 
obstetric practice two tertiary care hospitals in Gulba. 2010;I(3):1006-10.

3. Bhagat SB, Patil KC. International Journal of Research in Analysis of the current trend in the prescription of anti-hypertensive drugs among pregnant females in a tertiary care hospital. 2014;3(4):358-65.

4. Folic M, Folic N, Varjacic M, Jakovljevic M, Jankovic S. Review article Antihypertensive drug therapy for hypertensive disorders in pregnancy. Acta Medica Median. 2008;47(3):65-72.

5. Hypertension G, Blockers CC, Blocker AR. A study on prescribing pattern of antihypertensive drugs during pregnancy in tertiary care hospital, Bangalore. Anju AS, Peter Kandel, Dr. Praveen Kumar, K. Ramkumar, Dr. B. A Viswanath. 2016;6(09).

6. Bozzuto G, Ruggieri P, Molinari A. Molecular aspects of tumor cell migration and invasion. Annali dell'Istituto superiore di sanitÂ. 2010;46:66-80.

7. Patel R, Baria H, Patel HR, Nayak S. A study on pregnancy induced hypertension and foetal outcome among patient with PIH at tertiary care hospital, Valsad. 2017;4(11):4277-81.

8. Moser M, Brown CM, Rose CH, Garovic VD. Hypertension in pregnancy: Is it time for a new approach to treatment? J Hypertens. 2012;30(6):1092100.

9. Gaidhankar SL, Pore SM, Deokate MN, Ramanand SJ, Salunke AT. A study of drug utilization in indoor patients of high-risk pregnancy in a tertiary care hospital. Int J Basic Clin Pharmacol. 2016;5(4):136671.
10. Yadav S, Evangeline GS. a Study on Prescribing Patterns of Drugs in Pregnant Women Attending a Teaching Hospital. 2016;6(1):9-26.

11. Sharma R, Kapoor B, Verma U. Drug utlization patten during pregnancy in north India. Indian $\mathbf{J}$ Med Sci. 2006;60(7):277-86.

12. Sarita J, Bhupinder B. Evaluation of Antihypertensive Therapy of Pregnancy Induced Hypertensive (Pih) Patients in Mahila Chiktsalaya, Jaipur. 2011;2(1):510.

13. Kumar TN, Tadvi NA, RK. Prescription pattern of drugs in pregnancy induced hypertension in a tertiary care hospital. Int J Basic Clin Pharmacol [Internet]. 2013;2(6):783. Available at: http://www.scopemed.org/?mno=45442

14. Sajith M, Nimbargi V, Modi A, Sumariya R. Incidence of pregnancy induced hypertension and prescription pattern of antihypertensive drugs in pregnancy. Intranational J pharma Sci Res. 2014;5(04):163-70.

15. Jagadeesh K, Doctor M. Research Article Drug Utilization Evaluation in Diabetic Patients in a Tertiary Care Teaching Hospital: A Prospective Observational Study. 2014;4(5):147-51.

Cite this article as: Lahamate SB, Razvi SU, Baig MS, Doifode SM. Drug utilization study of antihypertensive drugs used in the treatment of second and third trimester of pregnancy in tertiary care hospital. Int J Basic Clin Pharmacol 2018;7:1733-7. 